of the fact that some of the deepest shocks are among the largest recorded".

Further evidence arises from a study of the density variation within the earth. I have shown ${ }^{7}$ that unless there is a change of material at a depth of the order of several hundred kilometres, the deduced moment of inertia of the central core would involve a most improbable distribution of matter. Jeffreys ${ }^{5}$ put forward the suggestion that the corresponding density jump found by me might be associated with a high-pressure modification of olivine. Bernal ${ }^{8}$, arguing by analogy from known properties of magnesium germanate, pointed out that such a modification might take the form of a complete change in the crystal type of olivine to a cubic form. The results of Price and Lahiri indicate a change in the value of $x$ from about $10^{-15}$ to at least $10^{-11}$ electromagnetic units. It does not seem unreasonable to suppose that this figure may fit the postulated cubic form of olivine at the temperature and pressure reached.

It appears thus that a number of distinct lines of evidence are in good accord in suggesting a change in properties at a depth of order $500-700 \mathrm{~km}$. below the earth's surface.

K. E. Bullen.

Department of Mathematics, University College, Auckland, N.Z. July 22.

1 Price and Lahiri, Proc. Roy. Soc., A, 165, S.55 (1938).

\& Byerly, Bull. Seismol. Soc. Amer., 16, 209 (1926).

s Jeffreys and Bullen, NATuRE, 131, 97 (1933); Bur. Cent. Séism. Trav. Scient., 11 (1935).

- Lehmann, Geod. Inst., Copenhagen, 5 (1934).

- Jeffreys, Mon. Not. Roy. Astro. Soc., Geophys. Suppl., 4, 57 (1937).

- Gutenberg and Richter, Bull. Geol. Soc. Amer., 49, 285 (1937).

7 Bullen, Mon. Not. Roy. Astro. Soc., Geophys. Suppl., 3, 395 (1936) Trans. Roy. Soc. N.Z., 67, 121 (1937).

- Bernal, Observatory, 59, 268 (1936).

\section{Transparent Models to Illustrate Geological Structures}

LARGE transparent models to show the structures of particular areas have been used for some years. So far as I am aware, they are less common in Britain than on the Continent; for example, at Lille, large models of this type have been made to show the structure of French coalfields. These models have been built up by drawing numerous accurate sections to scale, each on a separate glass sheet, and arranging these vertically at proper intervals.

Such models are invaluable to indicate underground structures to thcse not familiar with geological maps and sections, and they are also helpful as a check on suggested interpretations of complicated areas. Recently similar but smaller models of much simpler construction have been made. As they appear to be useful in the teaching of elementary geology and are quite inexpensive, a description may be useful to others. Similar models may also be employed for demonstrating other structural relations.

The model illustrated consists of a glass box, 6 in. $\times 7$ in. $\times 3 \frac{1}{2}$ in., formed by four glass sheets fastened with 'Seccotine' and fitted into slots in a wooden base. Over the top is a sheet of 'Cellophane' fastened along the edges by 'Durofix'. This upper sheet, on which the geological map may be drawn, is cut by thirteen narrow slits, each vertically above a V-shaped groove in the wooden base. Thirteen sheets of celluloid with successive sections across the structure represented are thus kept vertically in their positions, and can readily be taken out to demonstrate

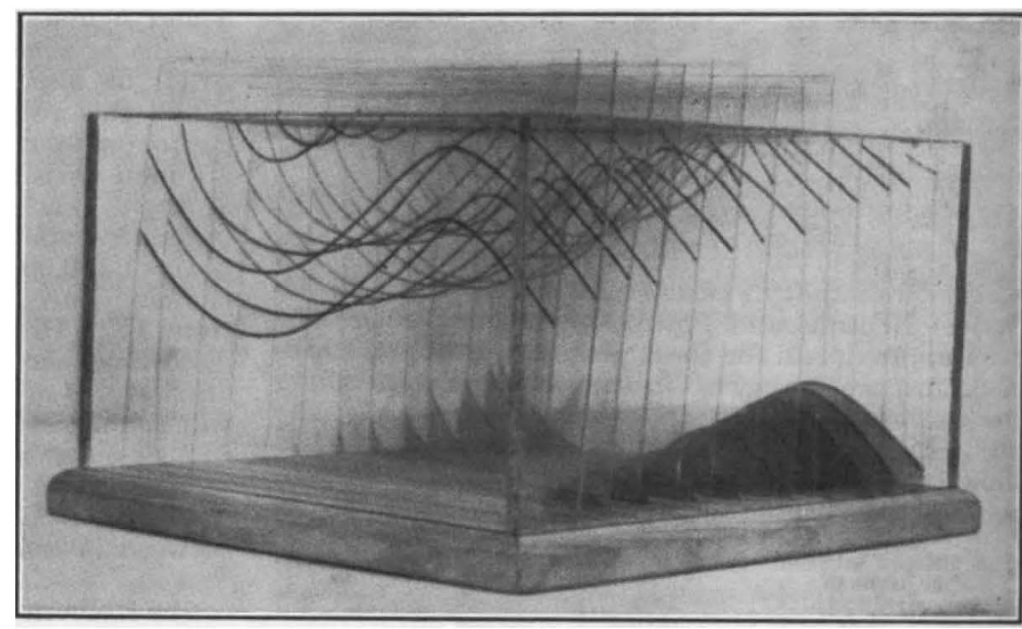

Transparent MODEL TO SHOW PITCHING Foldos

the section along any line. Viewed from the side, a model of this size is sufficiently transparent for the whole structure to be seen in three dimensions ; about a dozen sheets of celluloid seems to be the maximum number which can suitably be employed, but this depends on the amount of detail to be shown.

Geology Department,

A. E. Trueman.

University of Glasgow. Sept. 8.

\section{Antiquity of the Modern Type of Man}

Mr. Marston's discovery of parts of a human skull deep in the gravel of the 100-ft. terrace of the Lower Thames at Swanscombe is of great importance and significance. Thanks to the careful and scientific manner in which this discovery was treated by him, there can remain no doubt that these human bones were indeed in situ in the gravel and formed an integral part of it.

The Swanscombe skull, according to the expert anatomists who have studied it, would appear to be of the modern type, while on archæological and geological grounds, the specimen is to be referred to the Acheulean period. Thus, it now seems established that, as certain students of ancient humanity have held for many years, the primitive NeanderthalMousterian man was preceded in time by people closely akin in their bodily form to ourselves. The discovery of the Swanscombe skull therefore once more opens up, and in a decisive manner, the question of the antiquity of the modern type of man. Mr. Marston's discovery is, however, not the only example of human bones of this general type claimed to have been found in Acheulean and earlier deposits. But it has been the custom to regard it as necessary that any human bones claimed as of great antiquity must, in order to be accepted, and in addition to the 